九州大学学術情報リポジトリ

Kyushu University Institutional Repository

\title{
Bottom-up Effects of Crop Seeding Methods on Densities of the Alfalfa Weevil Hypera postica and Its Introduced Parasitoid Bathyplectes
} anurus

Nakah i ra, Kengo

Laboratory of Insect Natural Enemies, Institute of Biological Control, Faculty of Agriculture, Kyushu University

Iwase, Shun-ichiro

Laboratory of Insect Natural Enemies, Division of Biological Control, Department of Applied Genetics and Pest Management, Graduate School of Bioresource and Bioenvironmental Sciences, Kyushu University

Takagi, Masami Laboratory of Insect Natural Enemies, Division of Biological Control, Department of Applied Genetics and Pest Management, Graduate School of Bioresource and Bioenvironmental Sciences, Kyushu University

https://doi.org/10.5109/27357

出版情報: 九州大学大学院農学研究院紀要. 58 (2)，pp.277-280，2013-09. Faculty of Agriculture， Kyushu University

バージョン :

権利関係 : 


\title{
Bottom-up Effects of Crop Seeding Methods on Densities of the Alfalfa Weevil Hypera postica and Its Introduced Parasitoid Bathyplectes anurus
}

\author{
Kengo NAKAHIRA ${ }^{1 *}$, Shun-ichiro IWASE $^{2}$ and Masami TAKAGI ${ }^{2}$
}

Laboratory of Insect Natural Enemies, Institute of Biological Control, Faculty of Agriculture, Kyushu University, Fukuoka 812-8581, Japan

(Received April 26, 2013 and accepted May 9, 2013)

\begin{abstract}
The alfalfa weevil Hypera postica (Gyllenhal) is the most destructive pest of leguminous crops such as alfalfa, Chinese milk vetch, and hairy vetch throughout the world, including Japan. To control H. postica, the solitary endoparasitoid Bathyplectes anurus (Thomson) was released in Japan as a classical biological control agent. In our study, we investigated the bottom-up effects of hairy vetch seeding methods (i.e., control of seeding timing and density) on the $B$. anurus density to develop a field production method for $B$. anurus. The average densities of $H$. postica and $B$. anurus were significantly higher with early timing and a higher seeding density compared with early timing and a lower seeding density, late timing and a higher seeding density and late timing, and a lower seeding density. This confirmed that the densities of $H$. postica and $B$. anurus could be adjusted by the bottom-up effect of hairy vetch seeding methods. During the tri-trophic interaction among hairy vetch, $H$. postica, and B. anurus, the interaction between the hairy vetch weight and $H$. postica densities was high, whereas the interaction between the $H$. postica and $B$. anurus densities was very high. These results suggested that early timing and high density seeding indirectly enhanced the density of $B$. anurus by strong direct effects of the $H$. postica density on the $B$. anurus during the tri-trophic interaction. Overall, we concluded that a combination of early timing and high density hairy vetch seeding may facilitate efficient field productions of B. anurus.
\end{abstract}

Key words: classical biological control, green manure, honey source, tri-trophic interaction, weed control

\section{INTRODUCTION}

The alfalfa weevil Hypera postica (Gyllenhal) is the most destructive pest of alfalfa Medicago sativa (L.) in USA etc. (Radcliffe and Flanders, 1998; Moradi-Vajargah et al., 2011), and it also infects on the leguminous weeds Vicia angustifolia L., Trifolium repens (L.), and Melilotus officinalis (L.) (Byrne and Blickenstaff, 1968; Shobu et al., 2005). In Japan, H. postica is the most serious invasive pest of Chinese milk vetch Astragalus sinicus L., which is an important secondary crop in rice paddy fields (Shobu et al., 2005; Kuwata et al., 2005). Heavy infection with $H$. postica larvae dramatically damages the growth and honey production in Chinese milk vetch (Shobu et al., 2005; Kuwata et al., 2005). Pesticide applications are effective for controlling $H$. postica (Cummings et al., 2004), but their side-effects on honeybees and contamination of honey products are problematic (Shobu et al., 2005). Therefore, the solitary endoparasitoid Bathyplectes anurus (Thomson) (Hymenoptera: Ichneumonidae), an effective classical biological control agent against H. postica in the USA and Canada (Radcliffe and Flanders, 1998), has been released since 1991 and it is established in the Fukuoka Prefecture of Japan (Shobu et al., 2005). However, B.

${ }^{1}$ Laboratory of Insect Natural Enemies, Institute of Biological Control, Faculty of Agriculture, Kyushu University, Fukuoka 812-8581, Japan

${ }^{2}$ Laboratory of Insect Natural Enemies, Division of Biological Control, Department of Applied Genetics and Pest Management, Graduate School of Bioresource and Bioenvironmental Sciences, Kyushu University

* Corresponding author (E-mail: nakahira@agr.kyushu-u.ac.jp) anurus was collected only around the release area in Japan, more than a decade after its initial release in 2003 (Shobu et al., 2005) and later.

The slow spread of $B$. anurus has also been reported in the USA (Radcliffe and Flanders, 1998) and Canada (Harcourt, 1990). Therefore, large numbers of B. anurus cocoons or parasitized hosts were produced and collected from alfalfa fields to expand its distribution area, which were released into non-colonized areas (Radcliffe and Flanders, 1998). In Japan, the alfalfa is not a common crop. B. anurus occurs on Chinese milk vetch and leguminous weeds during spring in Japan (Shobu et al., 2005), but it is killed immediately by continuous cultivation and weed control in summer.

The hairy vetch Vicia villosa Roch, a leguminous host plant of alfalfa weevil (Byrne and Blickenstaff, 1968), is an agricultural agent that is used as a weed control (Campiglia et al., 2012), green manure in rice paddy fields (Sato et al., 2011), and a honey source for honeybees in weed lands and rice paddy fields (Morse and Calderone, 2000). These agricultural characteristics of hairy vetch make it suitable for rice farmers and honeybee keepers, although $B$. anurus production using hairy vetch and the cultivation methods of hairy vetch have not been studied. In our study, we selected hairy vetch as a candidate plant species for producing $B$. anurus, and we investigated the bottom-up effect of seeding methods (i.e., the control of timing and density) in hairy vetch on the $B$. anurus density to develop a field production method for $B$. anurus. We also evaluated the tri-trophic interaction among hairy vetch, $H$. postica, and B. anurus to elucidate the mechanism underlying the increase in $B$. anurus and to establish the method of collection 
and release of $B$. anurus.

\section{MATERIALS AND METHODS}

This study was conducted between July 2011 and May 2012 in an agricultural field located in Hisayama Town, Fukuoka Prefecture, Japan. The agricultural land was a weed land for five years before the experiment, and the field was plowed before the experiment was commenced in July 2011. The liquid herbicide N-(phosphonomethyl)-glycine potassium salt (192 ppm) was applied on September 5, 2011 to remove the weeds. Eight blocks were established in the farmland with $2 \mathrm{~m}$ intervals between each block on September 22, 2011 (Fig. 1). Hairy vetch seeds were sown on two dates (early timing: September 23, 2011; late timing: November 22,2011 ) and at two seeding densities (low density: $3.5 \mathrm{~g} / \mathrm{m}^{2}$; high density: $7.0 \mathrm{~g} / \mathrm{m}^{2}$ ). Late April is the most suitable period for estimating the damage to hairy vetch and estimating densities of $H$. postica and B. anurus in the Fukuoka Prefecture of Japan, because $H$. postica is in its mature larval or prepupal stages (Shobu et al. 2005). On April 23, 2012, a quadrat $(30 \mathrm{~cm} \times 30 \mathrm{~cm})$ was set five times randomly within each block and the plants with insects in each quadrat were cut and taken to the laboratory with paper bag. In the laboratory, the hairy vetch $V$. villosa, narrow-leaved vetch $V$. sativa subsp. nigra, and other plants from each quadrat were divided and weighed, and the damaged hairy vetch leaves per 100 leaves were counted in each quadrat. These plants were maintained in the laboratory to obtain H. postica adults and $B$. anurus cocoons until mid June. The number of emerged adult weevils and parasitoid cocoons were counted during mid June. No alfalfa weevils and introduced parasitoids were released onto the experimental site. Furthermore, no pesticides or water were applied to the plants on the farmland between September 6, 2011 and at the end of our study.

We defined the parasitism of $B$. anurus as the number of parasitoid cocoons / the number of host alfalfa weevil (i.e., emergence of adult alfalfa weevils plus parasitoid cocoons) based on laboratory rearing results using

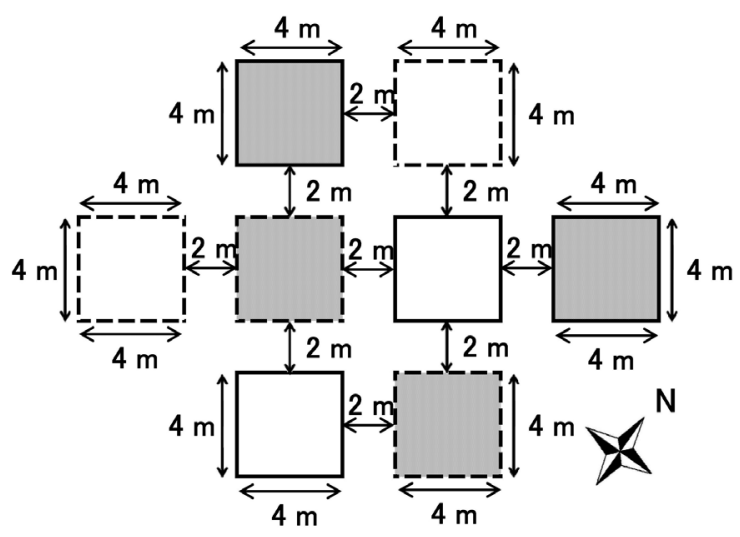

Fig. 1. Experimental design of hairy vetch seeding. Blocks with solid and broken lines indicate early and late seeding, respectively. Blocks with gray and white colors indicate low and high seeding density, respectively. the same method as Shobu et al. 2005. We used general linear models to investigate the effects of the timing and density of hairy vetch seeding on the following discrete response variables: the numbers of $H$. postica and $B$. anurus, the arcsine-transformed parasitism rate of $B$. anurus on $H$. postica, the arcsine-transformed leaf damage rates for hairy vetch, and the weights of hairy vetch, $V$. sativa subsp. nigra, and other plants in each quadrat. In these analyses, the categories of the seeding timing treatment (early or late), the categories of the seed density treatment (low or high) in each block, and the interactions of the two treatments were treated as explanatory variables. If the interaction of seeding timing and density treatments in the general linear model was significant at the 5\% level, a Tukey-Kramer multiple comparison test was used to analyze the average differences in the discrete response variables among treatment combinations. We used a simple linear regression to investigate the interactions between the weevil density versus the parasitoid density and hairy vetch weight versus the weevil density. All statistical analyses were conducted using JMP 6.0 for Windows (SAS Institute, 2008).

\section{RESULTS}

The densities of the emerged alfalfa weevil $H$. postica adults, parasitoid $B$. anurus cocoons, and host alfalfa weevils were significantly affected by the interactions between the timing and density of hairy vetch seeding at $P=0.05$ with $d f=1$ (emerged alfalfa weevil adults, $F=$ 7.5209; parasitoid cocoons, $F=9.6459$; weevil density, $F=$ 10.5323). The average densities of the emerged alfalfa weevil adults, parasitoid cocoon span and host alfalfa weevils were significantly higher with the early timing and high density seeding (ET and HD) treatment compared with the other three treatments (Tukey HSD multiple comparison test: $P<0.05$, Fig. 2). However, the parasitism of $B$. anurus on $H$. postica was not significantly affected by the timing and density of hairy vetch seeding and their interaction at $P=0.05$ with $d f=1$ (seeding timing, $F=0.6099$; seeding density, $F=0.6535$; interaction, $F=0.1910$; Fig. 3). Leaf damage rate of hairy vetch by $H$. postica was significantly affected by the interaction of the hairy vetch seeding timing and density $(d f=1$, $F=18.3043, P<0.05$ ). Leaf damage rate was significantly higher with the ET and HD treatment compared with the other three treatments (Tukey-Kramer multiple comparison test: $P<0.05$, Fig. 4). Hairy vetch weight per quadrat was correlated significantly with the host alfalfa weevil density per quadrat $\left(n=40, P<0.05, R^{2}=0.70\right)$. The density of $H$. postica per quadrat was correlated significantly with the density of $B$. anurus per quadrat ( $n=40$, $P<0.05, R^{2}=0.99$ ).

Weight of the hairy vetch $V$. villosa and the narrowleaved vetch $V$. sativa subsp. nigra was affected significantly by the interactions between the timing and density of hairy vetch seeding, with $d f=1$ (hairy vetch, $P=$ 0.0494, $F=4.1349$; narrow-leaved vetch, $P=0.0192, F=$ 6.0119). However, the weights of other plants were not affected significantly by the timing and density of hairy 


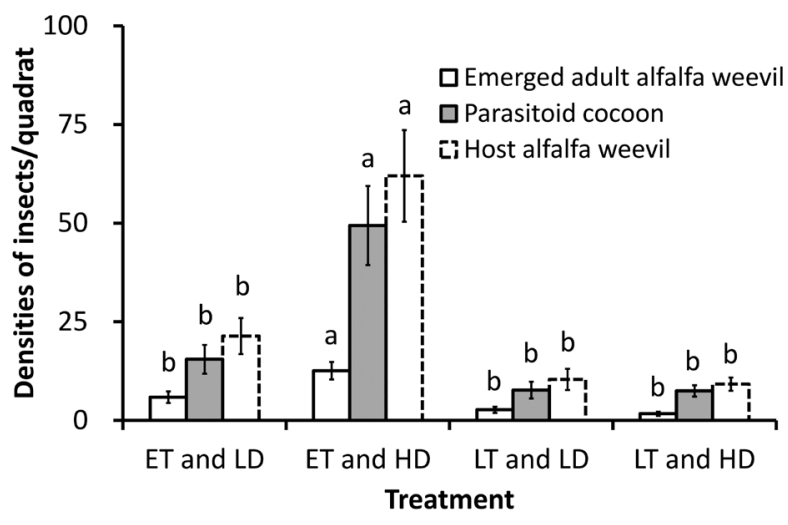

Fig. 2. Density (mean \pm standard errors) of emerged alfalfa weevil adults, parasitoid cocoons and host alfalfa weevils with each treatment. The bars capped with different letters differed significantly among treatments with each density $(P<0.05)$, according to Tukey-Kramer multiple comparison tests. Abbreviations: ET, early timing seeding; LT, late timing seeding; LD, low density seeding; HD, high density seeding.

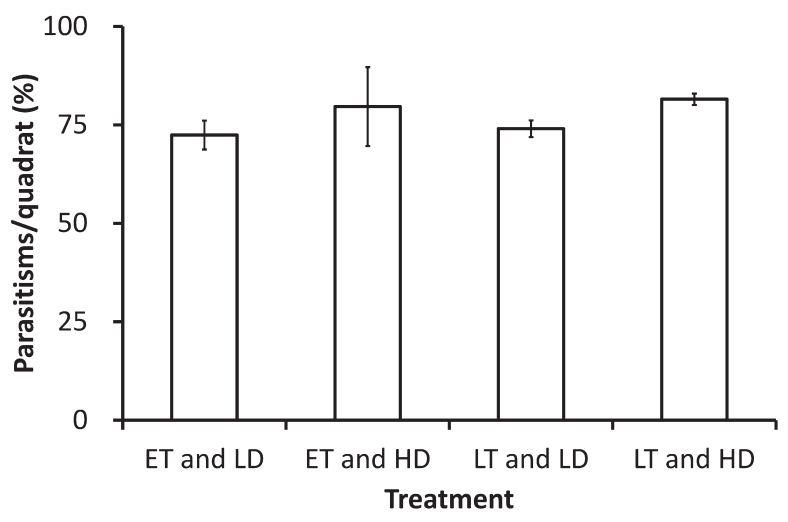

Fig. 3. Parasitism (mean \pm standard errors) of $B$. anurus on $H$. postica with each treatment. The treatments did not significantly affect the arcsin-transformed parasitism of $B$. anurus $(P>0.05)$, according to the general linear model analysis. Abbreviations: ET, early timing seeding; LT, late timing seeding; LD, low density seeding; HD, high density seeding.

vetch seeding and their interaction, with $d f=1$ (seeding timing, $P=0.1866, F=1.8124$; seeding density, $P=0.7698$, $F=0.0869$; interaction, $P=0.2635, F=1.2905$; Fig. 5). Average density of the hairy vetch was significantly higher with the ET and HD treatment compared with the other three treatments (Tukey-Kramer multiple comparison test: $P<0.05$, Fig. 4). However, the average density of the narrow-leaved vetch was not significantly different among the four treatments (Tukey-Kramer multiple comparison test: $P>0.05$, Fig. 5).

\section{DISCUSSION}

Density control of the alfalfa weevil $H$. postica and the parasitoid $B$. anurus was achieved successfully by the bottom-up effect of hairy vetch seeding methods. The ET and HD treatment significantly increased the

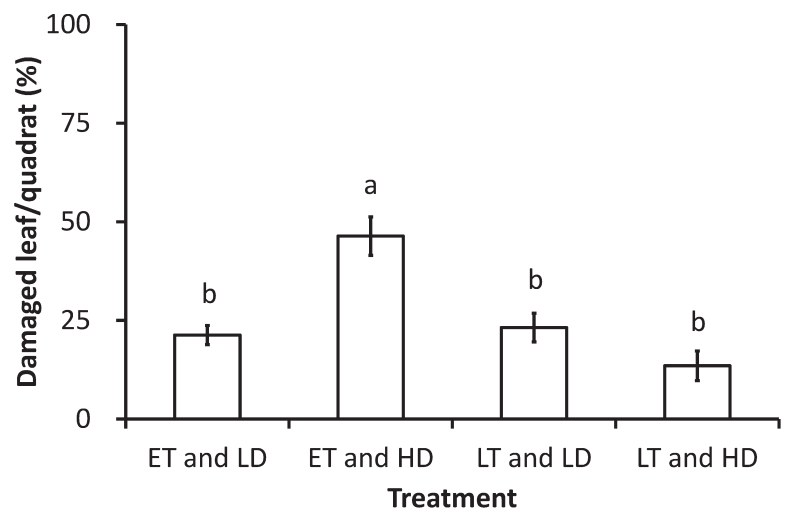

Fig. 4. Rate of hairy vetch leaf damage (mean \pm standard errors) with each treatment. The bars capped with different letters differed significantly among treatments $(P<0.05)$, according to the Tukey-Kramer multiple comparison tests. Abbreviations: ET, early timing seeding; LT, late timing seeding; LD, low density seeding; HD, high density seeding.

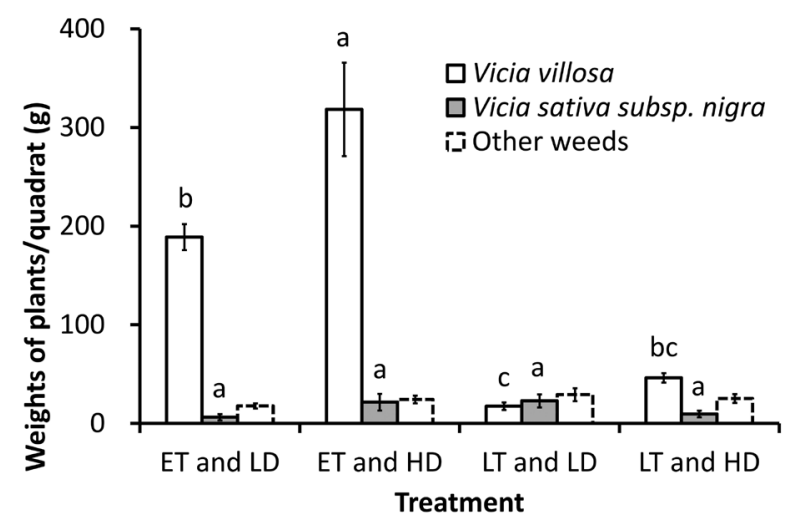

Fig. 5. Weight (mean \pm standard errors) of each plant category with each treatment. The bars capped with different letters for $V$. villosa and $V$. sativa subsp. nigra differed significantly among treatments $(P<0.05)$, according to the Tukey-Kramer multiple comparison tests. The treatment did not significantly affect the weights of other weeds $(P>0.05)$, according to the general linear model analysis. Abbreviations: ET, early timing seeding; LT, late timing seeding; LD, low density seeding; HD, high density seeding.

density of $B$. anurus compared with other treatments (Fig. 2), indicating that the ET and HD treatment could lead to efficient field production of $B$. anurus during hairy vetch cultivation. However, we must mention the effects of human disturbance on the production of $B$. anurus because there is a negative interaction between the annual biology of $B$. anurus and human disturbance in the hairy vetch fields. During spring in Japan, B. anurus develops from eggs to larvae, and then enters its summer diapause in cocoons on the ground surface (Shobu et al., 2005). During autumn, the summer diapause ends, and the parasitoids pupate to become adults, although remain in their cocoons and enter the winter diapause (Shobu et al., 2005). Thus, B. anurus passes the spring on hairy vetch and the summer and autumn in cocoons 
on the ground surface. However, majority of B. anurus on the ground are killed by soil cultivators and/or weed control during summer and autumn. To avoid human disturbances on $B$. anurus production, the products should be collected until early summer or maintained without soil cultivation and weed control. These avoidance methods will be easier in weed lands than rice paddy fields because the soil cultivation required for rice production begins during early summer.

The amount of hairy vetch can be controlled by the seeding timing and density because seeding significantly affected the weight of hairy vetch, whereas the ET and HD treatment significantly increased the weight of hairy vetch compared with the other three treatments (Fig. 5). The weight of hairy vetch was also highly correlated with the density of $H$. postica $\left(R^{2}=0.70\right)$, indicating that the density of $H$. postica can be manipulated by the control of hairy vetch. We also observed a high density interaction between $H$. postica and B. anurus $\left(R^{2}=0.99\right)$ and similar parasitism among the four treatments (Fig. 3). Therefore, we concluded that control of the B. anurus density was caused by a strong indirect interaction between $B$. anurus and hairy vetch and a strong direct interaction between $B$. anurus and $H$. postica. In this tri-trophic interaction, $B$. anurus is a species-specific parasitoid of $H$. postica, whereas $H$. postica can feed on various leguminous host plants (Radcliffe and Flanders, 1998; Shobu et al., 2005). The difference in the $R^{2}$ values for $B$. anurus versus $H$. postica and $H$. postica versus hairy vetch may be attributable to the differences in the food ranges of $B$. anurus and $H$. postica. In fact, we observed other host plants in addition to hairy vetch in the experimental area (Fig. 5). This co-occurrence of various host plants may have negative effects on the intensity of the interaction between $H$. postica and hairy vetch.

In our study, the ET and HD treatment significantly increased the density of $B$. anurus compared with other treatments due to the strong indirect effect of seeding methods and the strong direct effect of the H. postica density on the $B$. anurus density in this tri-trophic interaction. The results indicated that the ET and HD treatment will lead to efficient field production of $B$. anurus by the bottom-up effect. However, the ET and HD treatment significantly increased the density of $H$. postica and the damage to hairy vetch (Figs. 2 and 4), which indicated that this treatment risked heavy infections in the next year. Therefore, it is necessary to col- lect $B$. anurus and $H$. postica from hairy vetch fields and to release only $B$. anurus into non-colonized areas to mitigate and avoid any infection risks in the fields and non-colonized areas.

\section{ACKNOWLEDGMENT}

The authors would like to thank the apiarist Mr. Masaru Yabe for his kind help during our study.

\section{REFERENCES}

Blodgett, S. L., Lenssen, A. W., and S. D. Cash 2000 Harvest with ranking for control of alfalfa weevil (Coleoptera: Curculionidae). J. Entomol. Sci., 35: 129-135

Byrne, H. D., and C. C. Blickenstaff 1968 Host-plant preference of the alfalfa weevil in the field. J. Econ. Entomol., 61: 334-335

Campiglia, E., Radicetti, E., and R. Mancinelli 2012 Weed control strategies and yield response in a pepper crop (Capsicum annum L.) mulched with hairy vetch (Vicia villosa Roth.) and oat (Avena sativa L.) residues. Crop Prot., 33: 65-73

Cummings, D. C., Berberet, R. C., Stritzke, J. F., and J. L. Caddel 2004 Sod-seeding and grazing effects on alfalfa weevils, weeds, and forage yield in established alfalfa. Agron. J. 96: 1216-1221

Harcourt, D. G., 1990 Displacement of Bathyplectes curculionis (Thoms.) (Hymenoptera: Ichneumonidae) by $B$. anurus (Thoms.) in Eastern Ontario populations of the alfalfa weevil, Hypera postica (Gyll.) (Coleoptera: Curculionidae). Can. Entomol., 122: 641-645

Kuwata, R., Tokuda, M., Yamaguchi, D., and J. Yukawa 2005 Coexistence of two mitochondrial DNA haplotypes in Japanese populations of Hypera postica (Col., Curculionidae). J. Appl. Entomol., 129: 191-197

Moradi-Vajargah, M., Golizadeh, A., Rafiee-Dastjerd, H., Zalucki, M. P., Hassanpour, M., and B. Naseri 2011 Population density and spatial distribution pattern of Hypera postica (Coleoptera: Curculionidae) in Ardabil, Iran. Not. Bot. Hort. Agrobot. Cluj., 39: 42-48

Morse, R. A., and N. W. Calderone 2000 The value of honey bees as pollinators of U.S. crops in 2000. Bee Cult., 128: 1-15

Radcliffe, E. B., and K. L. Flanders 1998 Biological control of alfalfa weevil in North America. Integrated Pest Manag. Rev., 3: 225-242

SAS Institute 2008 JMP Statistics and graphics guide, Version 6.0. SAS Institute Inc., Cary, North Carolina, USA

Sato, T., Sato, E., Takakai, F., Yokoyama, T., and Y. Kaneta 2011 Effects of hairy vetch foliage application on nodulation and nitrogen fixation in soybean cultivated in three soil types. Soil Sci. Plant Nutr., 57: 313-319

Shobu, M., Okumura, M., Shiraishi, A., Kimura, H., Takagi, M., and T. Ueno 2005 Establishment of Bathyplectes anurus (Hymenoptera: Ichneumonidae), a larval parasitoid of the alfalfa weevil, Hypera postica (Coleoptera: Curculionidae) in Japan. Biol. Control, 34: 144-151 